REVISTA DE LITERATURA E CULTURA RUSSA

\title{
Intelligentsia e práticas autobiográficas na Rússia: Passado e pensamentos de A. Herzen
}

\section{Intelligentsia and autobiographical practices in Russia: A. Herzen's My Past and Thoughts}

Autor: Giuliana Teixeira de Almeida Edição: RUS Vol. 11. № 16 Data: Setembro 2020 


\section{Intelligentsia e práticas autobiográficas na Rússia: Passado e pensamentos de A. Herzen}

\section{Giuliana Teixeira de Almeida*}

Resumo: A autobiografia é um gênero essencialmente histórico. $\mathrm{Na}$ Rússia, onde grandes transformações históricas coexistiram com um grupo excessivamente sensível à História (a intelligentsia), a tradição autobiográfica se tornou muito forte e arraigada. 0 objetivo deste artigo é examinar a tradição autobiográfica na Rússia e analisar um dos textos fundadores dessa tradição: Passado e pensamentos de A. Herzen.

\begin{abstract}
Autobiography is a historical genre. In Russia, where substantial historical transformations coexisted with a group too sensitive to history (the intelligentsia), autobiographical tradition has become considerably deep and strong. This article aims to examine the Russian autobiographical tradition and examine one of its founding texts: A. Herzen's My Past and Thoughts.
\end{abstract}

Palavras-chave: Autobiografias; Intelligentsia; Herzen Keywords: Autobiographies; Intelligentsia; Herzen 


\section{A tradição autobiográfica na Rússia}

* Bacharel em História, Mestre e Doutora em Letras pelo programa de Literatura e Cultura Russa da Faculdade de Filosofia, Letras e Ciências Humanas da Universidade de São Paulo. Artigo resultante da Pesquisa "A Rússia na Encruzilhada Autobiográfica: Passado e pensamentos de A. Herzen", financiado pela Fundação de Amparo à Pesquisa do Estado de São Paulo (FAPESP); https:// orcid.org/0000-0003-0310-2283; giualmeida@yahoo.com.br
Na Rússia, o primeiro texto de caráter autobiográfico é atribuído a Avvakum Petrov (1620-1682), arcipreste da Igreja Ortodoxa russa que se notabilizou por liderar o grupo dos Velhos Crentes, que se separou da Igreja oficial para poder praticar livremente os antigos ritos russos, gerando uma grave crise institucional. Ele também se notabilizou como um dos precursores da moderna literatura russa ao escrever, entre outros textos, Vida (Jitie), por volta de 1673, considerada a primeira autobiografia russa. É interessante atentar para o fato de que quando as autobiografias começaram a se tornar mais frequentes na Rússia, durante o século XVIII, a palavra notas (zapíski) se tornou muito comum, e notas autobiográficas se tornou a forma mais recorrente de designação desse gênero textual.

No século XVIII muitos textos rotulados como notas autobiográficas foram escritos, inclusive por autoridades, como a czarina Catarina II (1729-1796), que escreveu a obra Notas da Imperatriz Catarina (Zapíski imperatrítsy Ekateríny). Mais textos surgiram no século XIX, período em qual o cânone autobiográfico russo despontou com obras clássicas do gênero, como por exemplo Passado e pensamentos (Bylóie i dúmy), de Aleksander Herzen. Contudo, é importante ressaltar que, para grande parte da intelectualidade russa - a intelligentsia -, a sensação era de que a Rússia se encontrava marginalizada do processo de florescimento da individualidade verificável na Europa Ocidental desde o Renascimento, que por sua vez é o fenômeno propulsor da escrita autobiográfica. De acordo com a visão hegemônica da intelligentsia russa oitocentista, a autocracia, a servidão, a censura e o fechamento da sociedade russa eram os grandes obstáculos ao desabrochar da personalidade.

O termo intelligentsia surge por volta de 1850 , da pena do romancista Boborýkin, mas sua difusão deve-se a Turguêniev, que o popularizou em seus escritos. O termo é difícil de definir, pois não existe nenhum grupo correspondente à intelligent- 
sia fora da Rússia e, por essa razão, foi utilizado erroneamente como sinônimo de da palavra "intelectuais". Esta associação é imprecisa pois, como a literatura sobre o assunto indica, em alguns momentos da história russa e em alguns casos específicos existiu uma fusão entre o intelectual e o intelligent, mas em outros não. Uma maneira de ilustrar essa não correspondência é lembrar que o intelectual que, por exemplo, ocupava um cargo na burocracia estatal e era apoiador do regime czarista jamais poderia ser considerado membro da intelligentsia. Outra dificuldade advém da origem distinta dos membros da intelligentsia. Não há nada que os homogeneíze - nem procedência de classe, nem grau de instrução - e apenas uma formação culta e uma postura combativa os aproxima, já que a "intelligentsia era menos uma classe do que um estado de espírito". ${ }^{1}$

Em um trecho de Passado e pensamentos, Herzen expressou aquilo que estava no cerne das preocupações da intelligentsia:

De modo geral, em Moscou começaram a despertar esses interesses intelectuais quando as questões literárias, vista a impossibilidade das políticas, tornaram-se vitais. A publicação de um livro notável tornava-se um grande evento. Líamos e comentávamos as críticas e as réplicas com a atenção que na França ou na Inglaterra é dedicada aos debates parlamentares. ${ }^{2}$

Portanto, além do compromisso com a ação política, o que forjava o laço entre os membros desse círculo e criava a noção de pertencimento era o repertório textual ao redor do qual esse grupo se formava. A leitura e o debate dos textos relevantes sobre a vida na Rússia eram as principais ações que engajavam os intelligents e favoreciam $o$ ato de associação. A comunidade de pessoas dependia, para se formar, de uma comunidade "textual", que a antecedia. Como escreveu Tibor

\footnotetext{
1 SZAMUELY, 1976, p. 173.

2 HERZEN, (http://az.lib.ru/g/gercen) Acessado em: 15/02/2018. "(...) Вообще Москва Входила тогда в ту эпоху возбужденности умственных интересов, когда литературные вопросы, за невозможностью политических, становятся вопросами жизни. Появление замечательной книги составляло событие. Критики и антикритики читались и комментировались с тем вниманием, с которым, бывало, в Англии или во Франции следили за парламентскими прениями".
} 
Szamuely, "o que os membros da intelligentsia tinham em comum - e que faltava à grande maioria dos seus compatriotas - era a sua formação livresca". ${ }^{3}$

É por isso que uma comunidade como essa, sensível à palavra escrita, ficou tão impactada pela publicação da carta filosófica escrita por Piotr Tchaadáiev, que tratava da Rússia como uma nação fora da História. Publicada em 1836 na revista Teleskóp, a Primeira Carta Filosófica de Tchaadáiev defendia que a Rússia não tinha nem passado nem presente, e estava apartada da contemporaneidade histórica que unia o mundo católico e protestante Ocidental. A constatação desesperançada do filósofo, que foi considerado oficialmente louco pelas autoridades russas, foi o motor do debate mais acirrado do século XIX, que dividiu a intelectualidade russa entre aqueles que defendiam que a Rússia deveria seguir os passos da Europa, com o objetivo de corrigir esse grave problema, e os que acreditavam que ela deveria se voltar para as suas tradições e buscar traçar seu desenvolvimento próprio. Um outro efeito da carta foi dar origem a um grupo que acreditava que a "juventude" da Rússia deveria ser aproveitada como um instrumento para que o país se abrilhantasse e despontasse como a nação do futuro.

Todos esses problemas ajudaram a criar uma obsessão nacional pela História e pelo futuro da Rússia, e a consciência histórica dos membros da classe preocupada com essas questões - a intelligentsia - se tornou hipertrofiada. Isso explica o grande entusiasmo dessa classe pelas ideias de Hegel que, ao penetrarem na Rússia na primeira metade do século XIX, tiveram um impacto ímpar, e que autores tendem a apontar como algo sem precedentes até mesmo na Europa Ocidental. Nos salões literários-filosóficos de Moscou e São Petersburgo, o pensamento de Hegel era debatido "não apenas como um conjunto de ideias, mas como um guia para a vida pessoal e coletiva". 4

A filosofia de Hegel foi um dos muitos estímulos para que os intelligents, compreendendo seus círculos como um es-

3 SZAMUELY, 1976, pp.172, 173.

4 HELLBECK, 2004, p. 281. 
tágio necessário da História em franco movimento dialético, assumissem o papel dos arautos da Rússia do futuro. Nesse sentido, a ideia de uma consciência que se desenovela através da História foi convertida em um chamamento para que os intelligents se tornassem os portadores de uma consciência histórica que colocasse em xeque o atraso e obscurantismo da vida russa sob o reinado de Nicolau I.

\section{A noção de personalidade na Rússia}

É contra esse pano de fundo que a noção de personalidade aflora na Rússia, dotada de uma urgência e de uma centralidade ímpar no contexto do século XIX. Assim,

A noção de personalidade estava no centro das suas discussões [dos intelligents]. A intelligentsia russa emergente entendia a personalidade primeiramente como um barômetro do desenvolvimento histórico que mensurava o grau de desenvolvimento moral e de libertação de uma ordem social dada. Sob as condições de atraso social e político que prevaleciam na Rússia, a personalidade abarcava um significado particular como motor do progresso. ${ }^{5}$

Tendo em vista essa noção tão particular de personalidade, entre os membros da intelligentsia russa o que imperava era a crença de que o dever do indivíduo crítico e moralmente livre era dedicar integralmente sua vida à emancipação da sua própria personalidade, pois essa não era uma missão que beneficiaria apenas a ele próprio, mas sim ao desenvolvimento da consciência histórica capaz de impulsionar a História para o progresso e a Rússia para o futuro almejado. Além disso,

$\mathrm{O}$ fato de a Rússia ainda estar em defasagem histórica e da personalidade ainda estar em sua fase embrionária (Bielínski) apenas reforçou a missão dessa auto atribuída vanguarda moral de viver uma vida socialmente responsável e historicamente consciente. ${ }^{6}$

Vissarion Bielínski acreditava que na Rússia de 1847 a personalidade estava apenas começando a sair de um estado em-

5 HELLBECK, 2004, p. 282.

6 HELLBECK, 2004, p. 282. 
brionário. Ainda sem se utilizar de uma terminologia padronizada, ora recorrendo à ideia de personalidade (lítchnost), ora à ideia de individualidade (individuálnost), o célebre crítico defendia que era dever de todos os homens transcender a subjetividade restrita e egoísta inerente ao ser humano e se dedicar ao desenvolvimento de uma subjetividade mais profunda, humana e dotada de responsabilidade social. Essa concepção englobava os valores estéticos defendidos por Bielínski, para quem o artista deveria perseguir o comprometimento moral na sua vida e obra, uma vez que, na visão do crítico, a qualidade artística da obra de arte era indissociável da sua mensagem em prol da transformação social.

A ideia de viver uma vida exemplar era a obsessão de muitos desses homens e mulheres da intelligentsia, que acreditavam no seu poder de influência sobre os outros. O caso mais emblemático é o de Herzen, já mencionado neste artigo, que junto com Bielínski foi um dos idealizadores da ideia da personalidade como historicamente determinada e preenchida de responsabilidade social. Herzen, um dos nomes mais destacados da geração que se dedicou à emancipação da personalidade, aprofundou as visões de Bielínski e condicionou a essa emancipação à ideia de ação e transformação do status quo. E também foi o responsável por fomentar a instituição da tradição cultural russa que surgiu como um desdobramento natural dessa concepção tão particular de personalidade: as práticas autobiográficas.

\section{A intelligentsia e as práticas autobiográficas}

Certos textos produzidos por membros da intelligentsia trilhavam uma via de mão dupla: ao mesmo tempo em que reproduziam códigos próprios do grupo, também criavam novos padrões e temas para serem perseguidos pelos companheiros, simultaneamente fomentando e forjando essa tradição. Passado e pensamentos é um caso exemplar nesse sentido. Se por um lado, a autobiografia de Herzen não descortinou um tema novo para o repertório textual da intelligentsia, uma vez que 
a intimidade era matéria cara aos membros desse grupo, por outro lado, ela forneceu um modelo bem-sucedido de inserção do indivíduo na História por meio da narração das vivências pessoais. ${ }^{7}$

O século XIX russo foi marcado pela emergência de uma consciência histórica e de si que foi desenvolvida em diversos textos de cunho memorialístico como diários, correspondências, autobiografias etc., que circulavam entre os membros da intelligentsia. Como exemplo, podem ser mencionados a obra de Pável Ánnenkov A década extraordinária: memórias literárias, o diário de Turguêniev, que foi publicado de 1830 a 1840 em revistas com o título Crônicas de um russo, ou ainda as memórias de Avdótia Panáieva, entre muitas outras obras similares.

A intelligentsia se formava e sociabilizava na dinâmica de pequenos círculos, muitas vezes compostos por pessoas próximas, como amigos e parentes, que se reuniam quase sempre em ambientes domésticos, geralmente salões de damas esclarecidas ou mesmo na residência de algum dos seus membros. É importante salientar que um aspecto que definia a intelligentsia era a sua alienação voluntária do restante da sociedade, a opção por viver em um mundo próprio e a total ruptura com o poder instituído.

Assim, uma vez que a intelligentsia, em função da sua oposição ferrenha ao czarismo, optava por se retirar da esfera pública institucional, consequentemente ela recolhia-se à esfera privada. Uma das consequências dessa atuação restrita aos pequenos círculos domésticos foi a emergência da intimidade (do pessoal) como matéria natural de reflexão. As fronteiras entre o público e o privado se diluíam naqueles pequenos ambientes frequentados por pessoas próximas que compartilhavam intensamente suas vidas e projetos. E, entre os projetos mais caros à intelligentsia figurava, acima de tudo, o compromisso de combater o poder instituído e assim transformar a sociedade.

7 Segundo Irina Paperno, o texto de Herzen também é o grande modelo para os textos memorialísticos/autobiográficos que inundaram a Rússia durante e após o término da União Soviética. 
Como afirmou Szamuely, a intelligentsia "só podia encontrar sua felicidade na imaginação de uma sociedade ideal ainda por nascer", ${ }^{8}$ e ela creditava para si um papel fundamental no forjamento dessa sociedade. É por essa razão que a transformação social e o caminhar da História jamais abandonavam o horizonte de preocupações desse grupo. Se, por um lado, a intelligentsia se debruçava sobre a intimidade e tudo aquilo que dizia respeito ao indivíduo, por outro lado o cerne das suas preocupações girava em torno do coletivo, já que esta buscava acima de tudo a transformação do status quo - o fim da servidão, o direito à liberdade de expressão do indivíduo etc.

Por conseguinte, as reflexões sobre o "eu" e sobre a vida não se descolavam das reflexões sobre os rumos e as vicissitudes da História, e a ideia de que a experiência individual importa e tem relevância histórica orientava a intelligentsia que almejava escrever sobre si. Assim, a autobiografia "funcionava como um meio que emprestava ao desenvolvimento da personalidade na História uma forma material ao mesmo tempo em que contribuía para o desdobramento da História". ${ }^{9}$ É por isso que as práticas autobiográficas alcançaram um lugar de destaque na tradição cultural russa.

A intelligentsia então vai desenvolver um apreço especial por esse tipo de texto a partir das décadas de 30 e 40 do século XIX, e esse hábito vai perdurar por todo o século XX e XXI. Os intelligents, com o objetivo de se tornarem modelos para 0 restante da sociedade, concluíram que as suas vidas não deveriam apenas ser vividas sem reparos, mas também deveriam ser registradas para que outros pudessem se inspirar nelas. E isso se configurou como o dever mais premente dos integrantes desse grupo. Portanto,

Conceber a sua vida pessoal como de natureza histórica, e esculpir sua autobiografia de maneira a fazer o eu se adequar às exigências da progressão histórica pode ser entendido como uma específica forma russa de prática autobiográfica. ${ }^{10}$

8 SZAMUELY, 1976, pp. 174, 175.

9 HELLBECK, 2004, p. 285.

10 HELLBECK, 2004, p.14. 
Assim, a segunda metade do século XIX foi marcada pelo aprofundamento da transformação do ideal de personalidade de um plano abstrato (do pensamento e da consciência crítica) para um plano mais concreto (da ação). Textos de caráter autobiográfico se tornaram os suportes literários ideias para os homens e as mulheres da intelligentsia que deliberadamente transformaram as próprias trajetórias individuais em um campo de resistência ao autoritarismo. Isso foi o que Herzen fez de forma bem-sucedida no texto Passado e pensamentos que, pela sua centralidade na tradição autobiográfica russa, merece uma análise mais atenta.

\section{Passado e pensamentos de A. Herzen}

Aleksandr Herzen nasceu em Moscou, em 1812 e faleceu em Paris, em 1970. Filho ilegítimo de um rico aristocrata, Herzen cresceu como um nobre e recebeu a educação típica dos membros da sua classe. Conforme foi amadurecendo, Herzen começou a tomar consciência das injustiças do seu país e dos privilégios da aristocracia e se rebelou contra o status quo. A leitura de textos proibidos ainda na juventude, a sua primeira prisão quando era um jovem aluno da Universidade de Moscou, as prisões e exílios aos quais foi submetido quando terminou a Universidade despertaram nele um ódio visceral contra a autocracia e o despotismo de Nicolau I. Em 1847 ele se exilou permanentemente na Europa, e no velho continente aprofundou sua inclinação política ao socialismo, tendo inclusive participado das revoluções que ocorreram nesse período, como é o caso da Revolução de 1848 na França. Na década de 1850, fixou residência em Londres e lá iniciou a primeira Imprensa Livre Russa (ILR), comprometida em libertar a palavra russa da censura. Todas as publicações da ILR tinham um programa político conhecido dos leitores e colaboradores: a luta pelo fim da servidão, pelo fim dos castigos corporais e pelo fim da censura.

Herzen foi um importante nome do pensamento revolucionário do seu tempo e se tornou uma figura central tanto entre os revolucionários europeus quanto entre a opinião pública 
progressista do seu país natal. Além de revolucionário, Herzen foi um escritor prolífico, e entre todas as obras que escreveu a mais importante é sua autobiografia Passado e pensamentos, que se transformou em uma obra canônica na Rússia.

A escrita de Passado e pensamentos começou em 1852 e só cessou em 1870 em função da morte de Herzen. Um dos aspectos mais interessantes de Passado e pensamentos é a preocupação que Herzen tinha de abordar tanto aquilo que era da ordem do privado quanto o que era da ordem do público. Essa preocupação já se esboça na introdução da autobiografia, quando ele escreve que "pode ser que Passado e pensamentos sirva para acertar as contas com a minha vida pessoal e acabe por sintetizá-la. O restante das meditações serve à ação, o restante das forças serve à luta". ${ }^{11}$ Portanto, apesar de existir vida interior e matérias próprias da intimidade em Passado e pensamentos, elas estão submetidas à lógica predominante do espelhamento e projeção de certos traços/aspectos pessoais no campo maior que interessa à Herzen, que é o das forças históricas.

Aferrado a esta ideia, Herzen transformou sua autobiografia literária em um retrato do seu tempo e, ao mesmo tempo, em um instrumento de transformação da sua época. É célebre a definição tardia que ele forneceu para o texto: "o reflexo da História em uma pessoa que acidentalmente esbarrou em seu caminho". ${ }^{12}$ Isso indica uma preocupação com algo que extrapola o próprio texto, e aqui podemos sugerir que é a relação entre o indivíduo e a História. Assim, a atração de Herzen pela autobiografia foi capitaneada exatamente pela vertente desse gênero que ultrapassa o mero plano literário, ou a dimensão restrita da literatura, e lança seus tentáculos sobre algo maior. Elsberg ressaltou que o texto pelo texto pouco interessava a Herzen, e chamou a atenção para a dimensão propagandística de Passado e pensamentos:

11 HERZEN, (http://az.lib.ru/g/gercen) Acessado em: 15/02/2018. "Пусть же Былое и Думы заключат счет с личною жизнью и будут ее оглавлением. Остальные думы - на дело, остальные силы - на борьбу".

12 HERZEN, (http://az.lib.ru/g/gercen) Acessado em: 15/02/2018"отражение истории в человеке, случайно попавшемся на её дороге". 
Herzen não queria se tornar apenas um escritor. A literatura autobiográfica o atraía exatamente porque ela não podia existir simplesmente como um caminho literário. Ele queria viver uma vida digna da narração autobiográfica. Herzen sonhava em se tornar o criador de uma autobiografia que se confundisse com a 'autobiografia da humanidade'. Desde cedo pressentiu que o seu trabalho autobiográfico seria um meio peculiar de propaganda [revolucionária]. Eles [seus textos autobiográficos] deveriam apresentar às pessoas uma vida dedicada à atividade e deveriam estar imbuídos vívida e brilhantemente da biografia da humanidade, de forma a encorajar os outros a se dedicarem também a uma vida de atividade, capaz de se emaranhar com a vida universal. ${ }^{13}$

Portanto, o texto em si, seu gênero, não era o que preocupava Herzen de imediato. Esse texto deveria ser o efeito colateral de uma vida merecedora do relato autobiográfico. Como já foi apontado, a preocupação com a emancipação da personalidade foi algo que obcecou Herzen e toda a sua geração. Desde a juventude, Herzen acreditava que cada momento da sua vida merecia ser biografado, ao passo que ele vivia corroborando esse objetivo de eternizar suas vivências. Vida e escrita da vida se influenciavam simultaneamente. Um exemplo dessa "autoimportância" atribuída a todas as etapas da sua existência pode ser apontada em uma carta que ele endereçou ao grande amigo de toda a vida, Ogarióv, não por acaso a quem ele dedicou a sua autobiografia:

A atitude de Herzen no que diz respeito à sua autobiografia é revelada ingenuamente numa carta que ele escreveu a Ogarióv com o objetivo de obter dele as cartas de juventude dos dois: - 'S [Sazónov] disse que você queimou as minhas cartas. Isso é péssimo. Teria sido melhor ter queimado um pedaço do mindinho da minha mão esquerda. Nossas cartas são os mais importantes documentos do nosso desenvolvimento; nelas, com a passagem do tempo, estão refletidas todas as modulações, ecoam todas as impressões das nossas almas. Oh, como você pôde queimar uma coisa dessas!'. Ogarióv, logicamente, havia destruído as cartas antecipando uma possível segunda visita da polícia, mas para o mais extravagante Herzen tais precauções de segurança eram secundárias tendo em vista a missão de registrar eternamente cada partícula da sua extraordinária existência. ${ }^{14}$

13 ELSBERG, 1956, p. 65. 
A ideia da eleição, ou a leitura de si próprio como um sujeito "predestinado", é uma ideia central que explica em grande medida a feitura e a razão de ser de uma obra como Passado e pensamentos. Na primeira parte da obra, quando introduz Ogarióv e descreve as lembranças do começo dessa amizade no período da infância, Herzen afirma: "estimávamos em nós mesmos o nosso futuro, olhávamos um para o outro como para jarros escolhidos, predestinados ${ }^{\prime 15}$. Na edição francesa de Passado e pensamentos, publicada pela Editions L'Âge D'Homme e traduzida e comentada por Daria Olivier, após a frase citada há um comentário que recupera um trecho de uma carta de Herzen para Ogarióv, datada de 5 de julho de 1833. Nessa carta, segundo a tradução francesa, Herzen afirma:

você ocupa um lugar fundamental na minha psicologia. Você e Tatiana Petrovna, vocês foram os dois seres que se deram ao trabalho de me compreender quando eu ainda era apenas uma criança, vocês foram os primeiros a se dar conta, desde aquela época, de que eu não seria apenas mais um em meio à multidão, mas seria único, original. ${ }^{16}$

Herzen identifica em Ogarióv o mesmo signo de eleição, a mesma predestinação a se distinguir da "multidão", e é esse traço em comum que os torna amigos:

a partir de 1827, nós nos tornamos inseparáveis. Em cada recordação daquele tempo, particular e comum a nós, em toda parte e em primeiro plano está ele, com seus traços de adolescente, seu carinho comigo. Logo foi possível vislumbrar nele aquele traço que não se encontra presente em muitas pessoas - para a tristeza, ou felicidade, não sei - mas sem dúvida para distinguir-lhe da multidão. ${ }^{17}$

No capítulo IV da primeira parte de Passado e pensamentos, Herzen empreende um salto temporal na narrativa: já entrado em anos, ele analisa a importância de Ogarióv no quadro com-

15 HERZEN, In: http://az.lib.ru/g/gercen. "Мы уважали в себе наше будущее, мы смотрели друг на друга, как на сосуды избранные, предназначенные».

16 HERZEN, , 1974, p. 447.

17 HERZEN. In: http://az.lib.ru/g/gercen "C 1827 мы не разлучались. В каждом воспоминании того времени, отдельном и общем, везде на первом плане он со своими отроческими чертами, со своей любовью ко мне. Рано виднелось в нем то помазание, которое достается немногим - на беду ли, на счастье, ли, не знаю, но наверное на то, чтоб не быть в толпе". 
pleto da sua vida pintado até aquele momento. Nessa análise retrospectiva, que entrecorta a narrativa destinada à infância, Herzen credita a Ogarióv o papel de protagonista na história da sua vida. Escreve Herzen:

Eis como, Ogarióv, de mãos dadas entramos juntos na vida! Nós seguimos sem medo e com orgulho, sem mesquinhez respondemos a cada chamado, com honestidade entregamo-nos às nossas paixões. $\mathrm{O}$ caminho que escolhemos não foi fácil, mas não nos desviamos dele nem uma vez; feridos, alquebrados, nós seguimos, e ninguém nos deixou para trás. Eu alcancei... não o objetivo final, mas esse lugar onde o fim da linha se aproxima, e involuntariamente busco sua mão para partirmos juntos , para apertá-la e dizer, com um sorriso melancólico: 'isso é tudo'.18

Da sensação de conclusão, com o seu "isso é tudo" retrocedendo até os anos da sua juventude, o ato de "memorializar" continuamente a vida foi algo que norteou a trajetória de Herzen. Por conseguinte, o desejo de não apenas se tornar um escritor, mas de viver e se tornar alguém "biografável", ou de conferir dignidade literária à sua vida cotidiana e concreta era algo muito pronunciado na concepção de mundo de Herzen. Todavia, isto não era uma característica apenas dele, mas da intelligentsia enquanto grupo, pois como já foi explorado neste artigo, na época de Herzen a escrita autobiográfica estava intrinsecamente relacionada à ideia do florescimento da personalidade que, por sua vez, era um conceito historicamente condicionado. Já sabemos que o conceito de personalidade surge na Rússia como uma medida de desenvolvimento da consciência histórica, como uma marca do tempo históri$c 0$, e que os membros da intelligentsia acreditavam que uma pessoa tinha o dever de dedicar a vida ao aprimoramento e à emancipação da própria personalidade, porque quanto mais desenvolvida essa se tornasse, mais chances esse indivíduo teria de influir positivamente no curso dos acontecimentos

18 HERZEN. Op. Cit. "Так-то, Огарев, рука в руку входили мы с тобою в жизнь! Шли мы безбоязненно и гордо, не скупясь отвечали всякому призыву, искренно отдавались всякому увлечению. Путь, нами избранный, был не легок, мы его не покидали ни разу. Раненые, сломанные, мы шли, и нас никто не обгонял. Я дошел... не до цели, а до того места, где дорога идёт под гору, и невольно ищу твоей руки, чтоб вместе выйти, чтоб пожать её и сказать, грустно улыбаясь - Вот и все". 
históricos. A grande contribuição de Herzen foi dar um tratamento artístico a esse anseio da sua época histórica por meio de uma obra que, por sua originalidade e grandeza, despontou como uma instituição na tradição literária russa e serviu de exemplo para gerações e gerações de homens e mulheres da intelligentsia.

\section{Referências Bibliográficas}

ELSBERG, Iakov. Herzen - Jizn i tvórtchestvo. Moscou: Khudójestvennaia literatura, 1956.

HERZEN, Alexandre. Passé et Méditations. Presenté, traduit et commenté par Daria Olivier. Lausanne: Éditions L'Age d'Homme, 1974.

HERZEN, Alexandre. Byloie i dumy. In: http://az.lib.ru/g/gercen. Acessado em: 15/02/2018.

HELLBECK, Jochen. "Russian Autobiographical Practice" in (Org.) Hellbeck, Heller. Autobiographical Practices in Russia. Berlim: V\&R Unipress, 2004.

MALIA, Martin. Alexander Herzen and the birth of Rusian Socialism. Nova York: The Universal Library, Grosset\& Dunlap, 1965.

PAPERNO, Irina. Stories of the Soviet Experience. Memoirs, Diaries, Dreams. Ithaca e Londres: Cornell University Press, 2009.

SZAMUELY, Tibor. La Tradition russe. Paris: Éditions Stock pour la Traduction Française, 1976.

Recebido em: 14/04/2020

Aceito em: 27/05/2020

Publicado em setembro de 2020 